Revista Tecnologia e Sociedade, Curitiba, v. 11, n. 23, 2015

ISSN (versão online): 1984-3526

ISSN (versão impressa): 1809-0044

\title{
Os impactos da Tecnologia da Informação e Comunicação no trabalho de auditoria fiscal: um estudo no âmbito de uma Secretaria de Fazenda
}

\author{
The impact of Information and Communication Technology in tax audit work: a study \\ under a Secretary of Treasure
}

\author{
Robson Augusto Dainez Condé ${ }^{1}$ \\ Renato Santiago Quintal ${ }^{2}$
}

Artigo submetido em mai./2015 e aceito para publicação em set./2015.

\section{RESUMO}

Esta pesquisa teve por objetivo analisar os impactos da Tecnologia da Informação e Comunicação (TIC) no trabalho do auditor fiscal, aferindo sua percepção sobre a influência da TIC na execução das atividades de auditoria e nos resultados do trabalho. Trata-se de investigação empírica de natureza qualitativa e quantitativa. A coleta dos dados foi realizada por meio de questionário enviado a 319 auditores da Secretaria de Fazenda do Estado do Espírito Santo, obtendo-se 121 respostas. Os resultados revelam a existência de relação estatística entre as variáveis investigadas, concluindo-se que a execução dos serviços e os resultados do trabalho de auditoria fiscal são impactados pela TIC. Em síntese, constatou-se que utilizar com frequência as ferramentas de TIC reduz o tempo de execução dos serviços, facilita a realização das tarefas, aumenta a produtividade no trabalho e reduz a sonegação fiscal.

Palavras-chave: Tecnologia; Sistemas informatizados; Auditoria fiscal; Gestão pública.

\begin{abstract}
This paper aimed to analyze the impacts of Information and Communication Technology (ICT) in the work of tax auditors, checking their perception about the influence of ICT in the implementation of audit activities and results of the work. These are empirical research qualitative and quantitative nature. Data collection was conducted through a questionnaire sent to 319 auditors from the Treasury Secretariat of Espírito Santo State, yielding 121 answers. The results reveal the existence of a statistical relationship between the variables investigated, concluding that the performance of services and the results of the tax audit work are impacted by ICT. In short, it was found that often use ICT tools reduces the time to perform the services, facilitates the tasks, increases productivity at work and reduce tax evasion.
\end{abstract}

Keywords: Technology; Computerized systems; Tax audit; Public management.

\footnotetext{
${ }^{1}$ Mestre em Ciências Contábeis pela Universadade do Estado do Rio de Janeiro - UERJ (2013). Bacharel em Direito pela Faculdade de Direito de Vila Velha (2008). Bacharel em Ciências Navais (Habilitação em Administração), pela Escola Naval (1995). Especialização em Administração (CIAW-1996). Aperfeiçoamento para Oficiais Intendentes_Gestão Pública (CIAW-1998). Exerceu os cargos públicos de Oficial da Marinha do Brasil, Auditor Fiscal de Tributos do Estado de Alagoas e, atualmente, é Auditor Fiscal da Receita do Estado do Espírito Santo. Têm experiência em Ciências Contábeis, em Administração Financeira e Orçamentária, em Processo Administrativo Fiscal (PAF) e em Fiscalização de Tributos. Email: robsonconde@hotmail.com

${ }_{2}^{2}$ Mestre em Ciências Contábeis (Faculdade de Administração e Finanças da Universidade do Estado do Rio de Janeiro); Especialista em Comércio Exterior (Instituto de Economia da Universidade Federal do Rio de Janeiro); Especialista em Gerenciamento de Projetos (Fundação Getúlio Vargas); Bacharel em Administração (Universidade Cândido Mendes) e em Ciências Navais, com Habilitação em Administração de Sistemas (Escola Naval). Atualmente é Oficial Superior da Ativa do Corpo Intendente da Marinha do Brasil, ocupa o posto de Capitão-de-Corveta e desempenha a função de Chefe do Departamento de Sistemas de Pagamento da Pagadoria de Pessoal da Marinha. Menbro do Corpo Editorial da Revista PAGMAR (ISSN 2318-1702 versão impressa e ISSN 2446-4791 versão online). Email: rsantiago79@hotmail.com
} 
Revista Tecnologia e Sociedade, Curitiba, v. 11, n. 23, 2015

ISSN (versão online): 1984-3526

ISSN (versão impressa): 1809-0044

\section{INTRODUÇÃO}

As organizações, para acompanhar as necessidades do mundo atual e aumentar sua competitividade, têm adotado novas tecnologias no ambiente de trabalho, alterando significativamente seus procedimentos operacionais. Recursos de Tecnologia da Informação e Comunicação (TIC), associados a robustos parques de informática, têm impactado diversas áreas do conhecimento e, ainda que não explorados em seu potencial, estão presentes na maior parte das atividades humanas, destacando-se pela capacidade de volume e velocidade no processamento dos dados.

Em um passado recente, alguns processos de negócio das organizações eram negligenciados, tendo em vista a limitação em lidar com o volume de informações geradas. Nos dias atuais, são insumos de sistemas de informação e controle interno das empresas e representam subsídio fundamental para tomada de decisão. Nesse contexto, ao analisar o desenvolvimento da atividade de auditoria, pode-se perceber a nítida influência da TIC nessa área, já que, há três décadas, a maioria das empresas usava calculadoras para efetuar o registro contábil de suas operações.

Para Fávero (2010), a perspectiva de mudança na Administração Pública, tornando-a efetiva na geração de bens e serviços à sociedade, está frontalmente associada à capacidade de transformar e aperfeiçoar suas estruturas e processos continuamente. Segundo Nasi (1997), a TIC tem contribuído para essa transformação, proporcionando o compartilhamento de informações por meio do emprego de equipamentos localizados nos mais distintos locais do planeta, de modo quase instantâneo. Entretanto, esta evolução também tem promovido e facilitado a ocorrência de fraudes, cada vez mais complexas em sua execução, dificultando o trabalho dos órgãos responsáveis pela fiscalização, controle e identificação dos atos ilícitos.

Esta pesquisa aborda essa temática na Administração Pública, especialmente na atividade de auditoria fiscal, onde empresas, por vezes, adotam práticas evasivas por meio da manipulação de suas demonstrações contábeis. Para minimizar os efeitos nocivos destas práticas, algumas mudanças têm sido implementadas, como, p. ex., a escrituração digital, que aumentou o controle do fisco sobre as atividades comerciais. Adicionalmente, encontra-se em curso o projeto da Nota Fiscal 
Revista Tecnologia e Sociedade, Curitiba, v. 11, n. 23, 2015

ISSN (versão online): 1984-3526

ISSN (versão impressa): 1809-0044

eletrônica (NF-e) de consumidor, cuja implantação contribuirá para desburocratização da atividade tributária, tornando mais fácil a escrituração contábil e o controle da documentação empresarial (BARROS et al., 2008).

Atualmente, no trabalho de fiscalização de uma empresa, o auditor fiscal se utiliza de informações e documentos (notas fiscais, livros fiscais, etc.) disponibilizados pelo contribuinte por exigência legal. Com esses documentos a autoridade fiscal desenvolve seu trabalho confrontando os valores movimentados, declarados e recolhidos pela empresa. Constatada alguma omissão ou divergência no recolhimento do tributo, o auditor fiscal atua corretivamente, para que a empresa recolha ao erário o valor devido, trabalho considerado padrão na auditoria fiscal de empresas privadas, até pouco tempo.

Com o advento do Sistema Público de Escrituração Digital (SPED), os registros contábeis das empresas passaram a ser feitos digitalmente, com notas fiscais eletrônicas padronizadas em todo o país. Hipoteticamente, um contribuinte que remete mercadorias de São Paulo para Alagoas, emite a NF-e da referida operação, cujo documento fica registrado em sistema eletrônico de processamento de dados, com acesso franqueado às Administrações Fazendárias.

Tais inovações modificaram o trabalho do auditor fiscal, demandando novas competências e habilidades desse profissional, um novo desafio para o fisco. Nesse contexto, o problema deste estudo pode ser assim enunciado: Qual o impacto das novas tecnologias da informação e comunicação no trabalho de auditoria fiscal? $\mathrm{O}$ objetivo é apresentar uma análise crítica das mudanças no trabalho do auditor fiscal, em virtude dos avanços tecnológicos e, para tanto, pretende-se traçar o perfil do profissional que atua na auditoria e identificar sua percepção sobre a TIC na execução de suas atividades e nos resultados de seu trabalho.

A escolha do tema surgiu em decorrência da alteração dos padrões fiscais influenciados pela evolução tecnológica, assim como, por sua capacidade de melhorar o trabalho de auditoria. A pesquisa está fundamentada na experiência dos autores em auditoria, bem como à luz da perspectiva teórica sobre as dimensões da estrutura causal proposta por Markus e Robey (1988). Ao apresentar o perfil do auditor fiscal e possibilitar a revisão dos processos de trabalho nessa área, o estudo se justifica pela contribuição que pode trazer para adoção de procedimentos alinhados às novas perspectivas da TIC na auditoria fiscal. 
Revista Tecnologia e Sociedade, Curitiba, v. 11, n. 23, 2015

ISSN (versão online): 1984-3526

ISSN (versão impressa): 1809-0044

\section{REVISÃO DA LITERATURA}

Um exuberante movimento de reformas no setor público iniciou-se na década de 1980, fundamentado na teoria do New Public Management (POLLIT; BOUCKAERT, 2009), denominada a Nova Gestão Pública (NGP) ou Nova Administração Pública (NAP). Tal dinâmica foi marcada pelo fortalecimento de práticas associadas à avaliação de desempenho e à eficiência, bem como à promoção da concorrência e de um estilo de gestão que enfatizava a liberdade gerencial, fragmentando a burocracia pública (BEVIR; RHODES; WELLER, 2003).

Com o desenvolvimento tecnológico, as organizações têm buscado inovações de TIC que melhorem seus resultados. Computadores e sistemas são cada vez mais imprescindíveis no mundo dos negócios e, assim como outras áreas do conhecimento, a área contábil tem sido impactada por estes aspectos. Cornachione (2001) menciona que é impossível ter um desempenho eficaz nas atividades econômicas, científicas e educacionais sem o apoio de tais ferramentas.

Markus e Robey (1988) realizaram estudo sobre teorias que justificam como e porque a tecnologia afeta 0 ambiente organizacional, concluindo que, embora existam estruturas teóricas que expliquem o seu papel nas mudanças organizacionais, apenas algumas podem ser utilizadas. Os autores, com base na literatura sobre o tema, apresentaram as seguintes dimensões de estrutura causal para analisar a relação entre mudança organizacional e tecnologia: agência causal, estrutura lógica e nível de análise. A Agência Causal aborda a natureza da causalidade, sugerindo que a mudança é originária de causas externas (imperativo tecnológico); ou que pessoas praticam suas ações com o fim de atingir os objetivos organizacionais (imperativo organizacional); ou, ainda, que a mudança emerge de maneira imprevisível na relação entre pessoas e eventos (a perspectiva emergente). A Estrutura Lógica se refere à natureza da relação entre os antecedentes e os resultados, compreendendo modelos de variância e modelos de processo. Por fim, o Nível de Análise está relacionado às entidades cujos conceitos e relações são abordados pela teoria, podendo se dar no nível micro (indivíduos), no nível macro (organizações e sociedade) ou misto. Esta pesquisa se desenvolve na perspectiva do imperativo tecnológico, reconhecendo a TIC como componente externo à organização que contribui efetivamente para as mudanças percebidas na estrutura. 
Revista Tecnologia e Sociedade, Curitiba, v. 11, n. 23, 2015

ISSN (versão online): 1984-3526

ISSN (versão impressa): 1809-0044

Especificamente na contabilidade, as mudanças na TIC foram inseridas em resposta à demanda do mercado e das diversas funções contábeis, como escrituração e análise de dados, profundamente impactadas nesse processo. Padovezze (2000) menciona que um dos reflexos desse desenvolvimento foi o aumento da automação: tarefas, originalmente manuais, como um lançamento contábil ou a escrituração de um livro fiscal, foram informatizadas, procedimento que, segundo Merchant (1998), contribui para evitar muitos problemas de controle, inconsistência ou falta de acurácia.

Nos últimos anos, a aceleração tecnológica viabilizou iniciativas na área pública orientadas ao emprego da TIC como alavanca da eficiência. Segundo Chrispino (2009) as discussões envolvendo o impacto da tecnologia sobre a sociedade vêm preenchendo espaços relevantes nos planos social, político e nas mídias, influenciando a participação de cidadãos na formulação de políticas públicas. Por outro lado, Rolt (2012) comenta que, a despeito de alguns progressos, a máquina estatal ainda permanece muito limitada em função de sua excessiva burocracia.

Especificamente neste trabalho, o tema analisado é de grande importância para a Administração Fazendária, cuja interface com a TIC deve ser estudada para avaliar sua influência nos processos de trabalho de auditoria fiscal. Torkzadeh e Doll (1999) reiteram a importância dos estudos desta natureza no nível operacional para mensurar a contribuição do usuário no sucesso do emprego das ferramentas tecnológicas. Os autores comentam ainda que a complexidade e a diversidade das organizações alteram a demanda por um determinado tipo de tecnologia e fazem com que sirva a diferentes objetivos organizacionais. No modelo industrial, p. ex., a TIC era empregada para aumentar a produtividade das empresas; posteriormente, a inovação e a satisfação do consumidor foram incluídas no modelo pós-industrial como temas importantes para o sucesso organizacional.

A capacidade de volume e velocidade no processamento dos dados são atributos que influenciam as organizações e afetam a forma de realização do trabalho (DELLAGNELO, 1991 apud PEREIRA; BECKER, 2003). A globalização, $p$. ex., como processo de integração é fruto dessa evolução tecnológica e, hoje, possibilita a transmissão e a recepção de informações instantaneamente, além da celebração de contratos por videoconferência entre pessoas situadas a milhares de quilômetros (CRUZ et al., 2003). Em pesquisa com bancos comerciais, Santos e 
Revista Tecnologia e Sociedade, Curitiba, v. 11, n. 23, 2015

ISSN (versão online): 1984-3526

ISSN (versão impressa): 1809-0044

Peffers (1991) identificaram que a implementação da TIC melhorou a eficiência e os resultados das organizações, impactando nos produtos, serviços e processos de negócios das instituições financeiras.

A despeito de proporcionarem a maximização das transações entre contribuintes e o aumento no volume de recursos movimentados, a evolução tecnológica e a globalização potencializaram também o surgimento de fraudes muito complexas em sua execução, um novo desafio para as Administrações no combate à evasão fiscal (FRANCISCO; RONCHI; MECHELN, 2008). Um importante estudo sobre motivação de atos fraudulentos foi apresentado por Donald Cressey (1953) ao entrevistar 200 condenados por crimes diversos, concluindo que as fraudes apresentaram, em comum, as seguintes características: a pressão, a oportunidade e a racionalização, vértices daquele que seria denominado o triângulo da fraude (CRESSEY, 1953 apud ACFE, 2012). A pressão floresce nos problemas financeiros enfrentados, p. ex., pelo gestor que se sente pressionado a apresentar uma melhor situação da empresa para os usuários das informações contábeis (CONDÉ, 2013) ou, ainda, por organizações que remuneram os funcionários com recompensas pelo aumento nos lucros, havendo, assim, maior propensão a manipulações das informações contábeis para aumentarem os resultados da empresa (ERICKSON et al., 2004); o segundo lado do triângulo da fraude é a oportunidade percebida para execução da ação, um fator facilitador da ocorrência de uma fraude; e, por fim, o último lado é composto pela racionalização, entendido como a forma pela qual o fraudador justifica seu ato; normalmente, alega sua inocência e considera aceitável a ação praticada.

Com o propósito de mitigar dificuldades para detecção da fraude fiscal, a Emenda Constitucional no. 42/2003 introduziu o inciso XXII, no artigo 37 da Constituição Federal, recomendando que a Administração Pública atue por meio de uma gestão integrada, com compartilhamento de informações fiscais. Sobreveio então o Sistema Público de Escrituração Digital (SPED), implementado pelo Decreto №. 6022/2007, que informatizou a relação entre o Estado e os contribuintes, com o objetivo de: i) promover a atuação integrada dos fiscos; ii) racionalizar e uniformizar as obrigações dos contribuintes; e iii) tornar célere a identificação de ilícitos tributários (FRANCISCO; RONCHI; MECHELN, 2008).

Para Silva (2012), o SPED acarreta para todos os envolvidos uma transformação cultural, orientada às inovações tecnológicas da era digital, 
Revista Tecnologia e Sociedade, Curitiba, v. 11, n. 23, 2015

ISSN (versão online): 1984-3526

ISSN (versão impressa): 1809-0044

permitindo maior clareza nas operações, mas, por tratar-se de inovação informacional, as consequências são complexas e aumentam o nível de exigência em todos os setores. Apesar dessa complexidade, Hendriksen e Breda (1999) comentam que a ciência contábil sempre se desenvolveu em resposta a novas descobertas, progressos tecnológicos e mudanças no ambiente.

Para enfrentar essa nova realidade e trabalhar com os dados gerados pela escrituração digital, as Administrações Fazendárias necessitam de pessoal qualificado para o uso das ferramentas de TIC. Assim, a presente pesquisa buscará identificar o perfil dos auditores da Secretaria de Fazenda do Espírito Santo e mensurar suas percepções quanto ao impacto da TIC na execução de suas atividades e nos resultados do trabalho desenvolvido. Adicionalmente, como forma de corrigir fragilidades na formação e capacitação desse pessoal, buscou-se coletar sugestões para melhorias na qualificação do auditor.

\section{METODOLOGIA}

\section{TIPO DE PESQUISA}

O presente estudo é uma investigação empírica de natureza qualitativa e quantitativa. Qualitativa por descrever o perfil dos profissionais que atuam na auditoria fiscal e as sugestões de melhoria nos processos de trabalho. Esse tipo de procedimento analítico é utilizado, principalmente, em pesquisas definidas como estudo de campo, estudo de caso ou pesquisa-ação, visando a apresentar características de determinada população ou fenômeno, ou estabelecer relações entre variáveis (GIL, 2009). A pesquisa é também quantitativa, por mensurar a percepção dos auditores sobre a utilização de ferramentas de TIC em seu trabalho.

No delineamento da pesquisa, o trabalho está enquadrado como um estudo de caso, caracterizado pela investigação profunda de um objeto para permitir o seu conhecimento amplo e detalhado (GIL, 2009). Trata-se de um caso empírico, inserido em um contexto de investigação do perfil do auditor fiscal de uma Secretaria de Fazenda e de sua percepção sobre a utilização das ferramentas de TIC na atividade de auditoria. 
Revista Tecnologia e Sociedade, Curitiba, v. 11, n. 23, 2015

ISSN (versão online): 1984-3526

ISSN (versão impressa): 1809-0044

A coleta dos dados foi realizada por meio de questionário elaborado na plataforma googledocs, contendo 1 sentença aberta e 11 sentenças fechadas, sendo 5 sobre o perfil dos respondentes e 6 envolvendo as seguintes variáveis em escala likert: i) percepção sobre a execução do trabalho de auditoria; e ii) percepção sobre os resultados do trabalho de auditoria. O questionário foi enviado a 319 auditores fiscais da Secretaria de Fazenda do Estado do Espírito Santo, que utilizam ferramentas de TIC na auditoria fiscal, obtendo-se 121 respostas $(38 \%$ do contingente investigado).

As respostas obtidas apresentaram um bom coeficiente de confiabilidade interna alfa de cronbach $(\alpha=0,887)$, valor que, segundo Streiner (2003), proporciona robustez à pesquisa. Em seguida, as respostas obtidas foram tabuladas para análise quanto às relações existentes entre as variáveis investigadas.

\section{INTERPRETAÇÃO E ANÁLISE DOS DADOS}

As informações coletadas foram segmentadas da seguinte forma: i) o perfil do auditor fiscal; ii) a percepção do auditor sobre as ferramentas de TIC na execução do trabalho de auditoria; e iii) a percepção do auditor sobre os resultados do trabalho de auditoria com os recursos de TIC utilizados, cujas respostas foram testadas estatisticamente. O perfil do auditor foi descrito pelas seguintes variáveis: sexo, idade, formação e tempo de experiência no trabalho, conforme Quadro 1.

\begin{tabular}{|c|c|c|c|}
\hline SEXO & IDADE & FORMAÇÃO & TEMPO DE SERVIÇO \\
\hline $\begin{array}{l}\text { *Masculino } \\
{ }^{*} \text { Feminino }\end{array}$ & $\begin{array}{l}* \text { Idade } \leq 30 \\
* 31 \leq \text { Idade } \leq 40 \\
* 41 \leq \text { Idade } \leq 50 \\
* 51 \leq \text { Idade } \leq 60 \\
* \quad \text { Idade } \geq 61\end{array}$ & $\begin{array}{l}\text { * engenharia } \\
\text { * economia } \\
\text { * direito } \\
\text { * administração } \\
\text { * ciências contábeis } \\
\text { * outras }\end{array}$ & $\begin{array}{l}{ }^{*} \text { mais de } 10 \text { anos } \\
{ }^{*} \text { menos de } 10 \text { anos }\end{array}$ \\
\hline
\end{tabular}

Quadro 1 - Perfil do auditor fiscal

A percepção quanto à execução do trabalho, descrita no Quadro 2, compreende o nível de dificuldade do auditor para o uso da TIC, a utilidade da TIC para o trabalho e sua contribuição para a velocidade de execução dos serviços.

\section{DESCRIÇÃO}

a) nível de dificuldade

b) utilidade

\section{CLASSIFICAÇÃO}

* é fácil utilizar os recursos de TIC no trabalho de auditoria fiscal; ou * não é fácil utilizar os recursos de TIC no trabalho de auditoria fiscal.

* os recursos de TIC disponibilizados pela SEFAZ são muito úteis ao trabalho de auditoria fiscal; ou

* os recursos de TIC disponibilizados pela SEFAZ não são muito úteis ao trabalho de auditoria fiscal. 
Revista Tecnologia e Sociedade, Curitiba, v. 11, n. 23, 2015

ISSN (versão online): 1984-3526

ISSN (versão impressa): 1809-0044

\begin{tabular}{ll}
\hline & * os recursos de TIC disponibilizados pela SEFAZ contribuem muito para \\
c) velocidade & $\begin{array}{l}\text { uma auditoria mais rápida; ou } \\
\text { pos recursos de TIC disponibilizados pela SEFAZ não contribuem muito } \\
\text { para uma auditoria mais rápida. }\end{array}$
\end{tabular}

Quadro 2 - Percepções do auditor sobre a execução do trabalho

A percepção do auditor fiscal sobre os resultados do trabalho realizado compreende a percepção sobre a acurácia (realização do trabalho sem erros), a produtividade do trabalho (volume de trabalho realizado) e a contribuição da TIC para a redução da sonegação fiscal, segundo a classificação proposta no Quadro 3.

\begin{tabular}{|c|c|}
\hline DESCRIÇÃO & CLASSIFICAÇÃO \\
\hline a) Acurácia & $\begin{array}{l}\text { * os recursos de TIC disponibilizados pela SEFAZ contribuem muito para a } \\
\text { realização de um trabalho de auditoria fiscal sem erros; ou } \\
\text { * os recursos de TIC disponibilizados pela SEFAZ não contribuem muito } \\
\text { para a realização de um trabalho de auditoria fiscal sem erros. }\end{array}$ \\
\hline b) Produtividade & $\begin{array}{l}\text { * os recursos de TIC disponibilizados pela SEFAZ aumentam muito a } \\
\text { produtividade do trabalho de auditoria fiscal; ou } \\
\text { * os recursos de TIC disponibilizados pela SEFAZ não aumentam muito a } \\
\text { produtividade do trabalho de auditoria fiscal. }\end{array}$ \\
\hline c) Sonegação fiscal & $\begin{array}{l}\text { * os recursos de TIC disponibilizados pela SEFAZ contribuem muito para a } \\
\text { redução da sonegação fiscal; ou } \\
\text { * os recursos de TIC disponibilizados pela SEFAZ não contribuem muito } \\
\text { para a redução da sonegação fiscal. }\end{array}$ \\
\hline
\end{tabular}

Quadro 3 - Percepções do auditor sobre os resultados do trabalho realizado

$\mathrm{Na}$ interpretação dos resultados foi utilizada a análise de frequência das variáveis sobre o perfil do auditor fiscal a fim de demonstrar a composição do quadro atual dos servidores. Nesse contexto, foi empregado o teste qui-quadrado $\left(\mathbf{x}^{\mathbf{2}}\right)$ para investigar a existência de relações entre duas variáveis deste perfil (sexo e tempo de serviço), o nível de utilização das ferramentas de TIC, bem como as variáveis descritas nos Quadros 2 e 3. Adotou-se a correção de Yates quando o valor esperado apresentou resultado menor que cinco em pelo menos uma das classes da tabela de contingência. Alternativamente, nos casos com células com valores iguais a zero ou quando o número de observações foi inferior a vinte casos, utilizou-se o Teste Exato de Fisher, todos realizados com o apoio do software Statistical Package to Social Sciences for Windows (SPSS). Na sentença aberta, utilizou-se a análise de conteúdo, voltada para descrição e interpretação de textos, cujas informações auxiliam na compreensão dos significados das mensagens (MORAES, 1999).

Adicionalmente, em relação aos dados coletados a partir dos questionários, foi delineada a análise multiparadigmal de Meyerson e Martin (1987), técnica que consiste em articular o relacionamento das percepções de determinado grupo com as perspectivas da Integração, Diferenciação e Fragmentação. 
Revista Tecnologia e Sociedade, Curitiba, v. 11, n. 23, 2015

ISSN (versão online): 1984-3526

ISSN (versão impressa): 1809-0044

A perspectiva da Integração indica a existência de percepções comuns aos respondentes, no que se refere aos diferentes aspectos examinados. A Diferenciação evidencia a presença de consenso somente dentro dos agrupamentos que compõem a organização e, por fim, a Fragmentação aponta para a ausência de conformidade dos componentes da organização (CARRIERI, 2008).

No que diz respeito à execução do trabalho, as hipóteses nulas testadas neste estudo são as seguintes:

$\mathrm{H}_{\mathrm{a}}$ : Não há relação entre o sexo do auditor e sua percepção sobre: i) o nível de dificuldade das ferramentas de TIC; ii) a utilidade das ferramentas de TIC; e iii) a velocidade de realização das tarefas.

$\mathbf{H}_{\mathrm{b}}$ : Não há relação entre o tempo de serviço do auditor e sua percepção sobre: i) o nível de dificuldade das ferramentas de TIC; ii) a utilidade das ferramentas de TIC; e iii) a velocidade de realização das tarefas.

$\mathbf{H}_{\mathrm{c}}$ : Não há relação entre o nível de utilização das ferramentas de TIC e a percepção do auditor sobre: i) o nível de dificuldade das ferramentas de TIC; ii) a utilidade das ferramentas de TIC; e iii) a velocidade de realização das tarefas.

Quanto aos resultados do trabalho, as hipóteses nulas testadas são as seguintes:

$\mathbf{H}_{\mathrm{d}}$ : Não há relação entre o sexo do auditor e sua percepção sobre:i) a acurácia proporcionada pelas ferramentas de TIC; ii) a produtividade do trabalho realizado com o apoio das ferramentas de TIC; e iii) a contribuição da TIC para a redução da sonegação fiscal.

$\mathbf{H}_{\mathrm{e}}$ : Não há relação entre o tempo de serviço do auditor e sua percepção sobre: i) a acurácia proporcionada pelas ferramentas de TIC; ii) a produtividade do trabalho realizado com o apoio das ferramentas de TIC; e iii) a contribuição da TIC para a redução da sonegação fiscal.

$\mathbf{H}_{\mathrm{f}}$ : Não há relação entre o nível de utilização das ferramentas de TIC e a percepção do auditor sobre: i) a acurácia proporcionada pelas ferramentas de TIC; ii) a produtividade do trabalho realizado com o apoio das ferramentas de TIC; e iii) a contribuição da TIC para a redução da sonegação fiscal.

\section{RESULTADOS E DISCUSSÃO}

PERFIL DOS AUDITORES 
Revista Tecnologia e Sociedade, Curitiba, v. 11, n. 23, 2015

ISSN (versão online): 1984-3526

ISSN (versão impressa): 1809-0044

O perfil dos respondentes foi descrito pelos atributos: idade, sexo, formação e tempo de experiência no trabalho. Quanto a faixa etária dos 121 participantes, observou-se que apenas 8 ( $7 \%$ do total) têm 30 anos ou menos; $20 \%$ tem entre 31 e 40 anos (14 com idade entre 31 e 35 anos, e 10 na faixa etária compreendida entre 36 e 40); $33 \%$ dos respondentes (40 auditores) têm idade entre 41 e 50 anos, sendo 11 entre 41 e 45 anos, e outros 29 com idade na faixa de 46 a 50; os demais respondentes ( $40 \%$ do total) estão com mais de 50 anos, sendo 34, 12 e 3 auditores nas faixas etárias de 51 a 55, 56 a 60 e mais de 60 anos, conforme Gráfico 1.

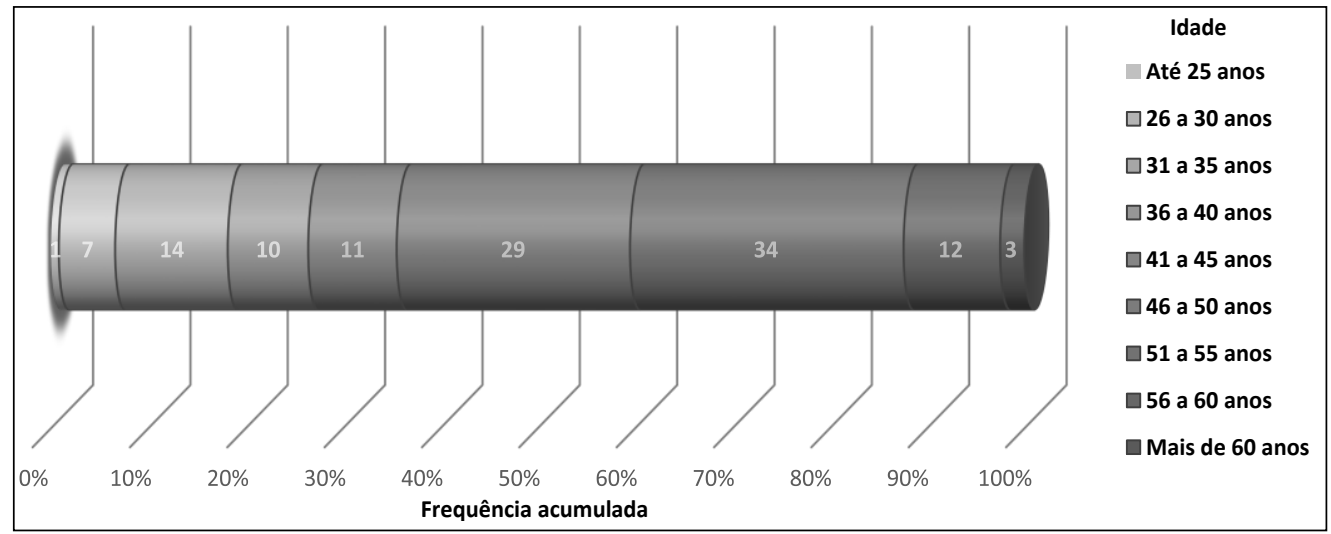

Gráfico 1 - Idade dos auditores

As informações constantes do gráfico demonstram que $73 \%$ dos respondentes (89 auditores) estão compreendidos na faixa etária que abarca adultos de meia idade (41 a 65 anos) e adultos idosos (idade superior a 65 anos). Nasri (2008), em estudo sobre o envelhecimento populacional, observa que o grupo etário composto por pessoas acima de 65 anos mostrou um crescimento nas últimas 3 décadas no Brasil, indicador influenciado pela redução na taxa de fecundidade e pelo aumento na expectativa de vida. Prevê ainda que, em 2050, esse grupo responderá por $19 \%$ da população brasileira, uma grande modificação na pirâmide populacional. Segundo Oliveira e Salles (2004), essa mudança no perfil da população implicará em um grande impacto na forma de gerir, capacitar e absorver o capital intelectual.

No que se refere à formação, pode-se perceber que um contingente significativo dos respondentes (72\%) possui formação em Ciências Contábeis (50 auditores) ou Direito (37 auditores), destacando-se, ainda, em proporção menor, as áreas de formação em administração e engenharia, conforme Gráfico 2. 
Revista Tecnologia e Sociedade, Curitiba, v. 11, n. 23, 2015

ISSN (versão online): 1984-3526

ISSN (versão impressa): 1809-0044

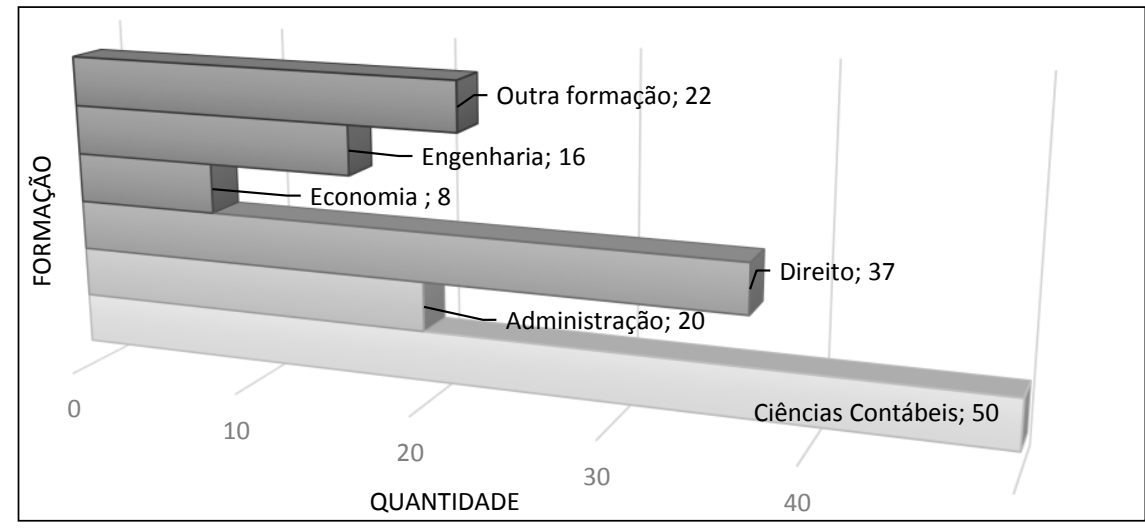

Gráfico 2 - Formação dos auditores

Segundo Moura, Silva e Dias (2004), a área de atuação do profissional contábil é extremamente abrangente, podendo sua atuação ser verificada no serviço público ou no setor privado. Vale destacar que 32 auditores (26\% dos respondentes) possui mais de uma formação, demonstrando que percentual significativo dos avaliados tem buscado desenvolver-se, melhorando sua capacitação.

No que tange ao sexo, identifica-se significativa predominância do sexo masculino, representado por $83 \%$ contra $17 \%$ dos respondentes do sexo feminino, conforme pode ser observado no Gráfico 3.

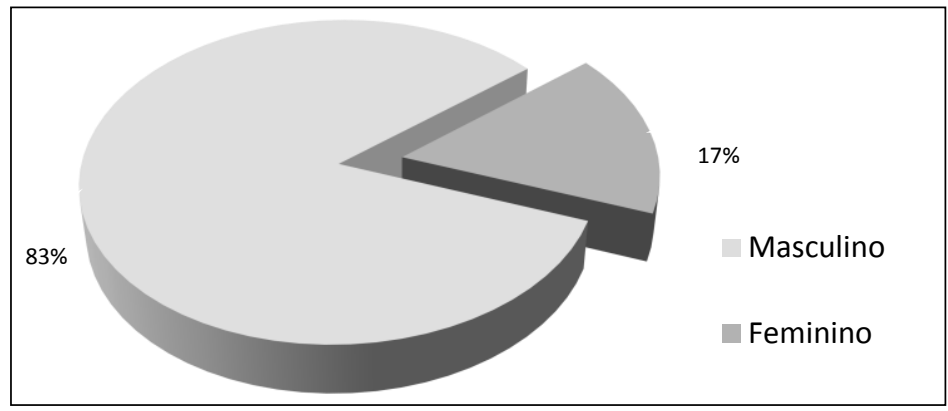

Gráfico 3 - Sexo dos auditores

Apesar da maioria dos respondentes ser composta por indivíduos com formação em ciências contábeis e constituída por representantes do sexo masculino, convém mencionar que a participação feminina nas atividades afetas ao saber contábil vem crescendo, conforme informações constantes do Balanço Socioambiental do Conselho Federal de Contabilidade (CFC) referente ao ano de 2010. Aquela pesquisa evidencia que, do total de profissionais ativos, $41,13 \%$ são do sexo feminino, correspondendo a um aumento de $4,13 \%$ em relação aos anos anteriores (2005-2009), quando o percentual correspondia a 37\%.

Quanto ao ano de ingresso na carreira, pode-se perceber que a maior parte dos respondentes é oriunda dos concursos de 1984 e de 1988 (55\%), seguida dos 
Revista Tecnologia e Sociedade, Curitiba, v. 11, n. 23, 2015

ISSN (versão online): 1984-3526

ISSN (versão impressa): 1809-0044

servidores que ingressaram no concurso de 2002 (28\%) e no concurso de 2008 (14\%). Essa diferença percentual pode ser explicada pelo lapso temporal entre a realização dos concursos, conforme apresentado no Gráfico 4. Essas informações sugerem a necessidade da realização de processos seletivos com maior frequência, a fim de proporcionar uma maior oxigenação dos cargos na organização, sem prejuízo para na qualidade do serviço realizado.

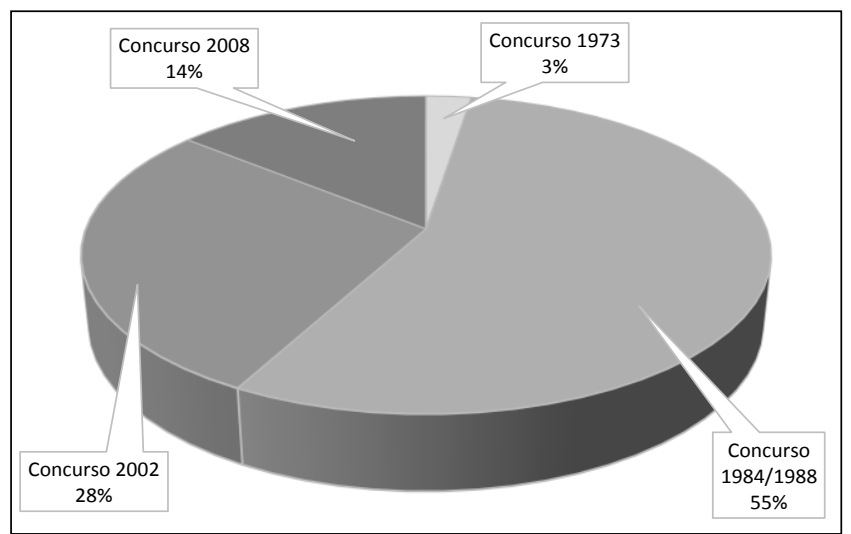

Gráfico 4 - Ano de ingresso dos auditores no Serviço Público

Evangelista (2010) registra que a evolução tecnológica se dá em um ritmo intenso e ocasiona sensíveis modificações na vida dos indivíduos, que têm dificuldades em acompanhar essas transformações, especialmente quando se trata da população idosa.

Para Viana (2012), tanto no setor público quanto no privado, em que pesem suas características distintas, descortina-se um desafio comum: a convivência entre gerações de trabalhadores com valores, motivações, demandas e comportamentos distintos. Nesse contexto, verifica-se que convivem na organização investigada várias gerações de trabalhadores, embora em quantidades proporcionais bem diferenciadas.

\section{PERCEPÇÃO SOBRE A EXECUÇÃO DO TRABALHO}

A percepção do auditor fiscal sobre a execução do trabalho foi representada nesta pesquisa pela velocidade dos serviços realizados, pelo nível de dificuldade e pela utilidade das ferramentas de TIC que, associados às variáveis sexo, tempo de serviço e nível de utilização dos respondentes, avaliaram por meio do teste quiquadrado $\left(x^{2}\right)$ a existência de relação estatisticamente significante entre elas. 
Revista Tecnologia e Sociedade, Curitiba, v. 11, n. 23, 2015

ISSN (versão online): 1984-3526

ISSN (versão impressa): 1809-0044

\begin{tabular}{|c|c|c|c|c|c|c|c|c|c|c|c|c|}
\hline \multicolumn{13}{|c|}{ Painel A - Nível de dificuldade } \\
\hline & \multirow[b]{2}{*}{ E } & \multicolumn{2}{|c|}{ Sexo } & \multirow[b]{2}{*}{$x^{2}$} & \multirow[b]{2}{*}{$\mathbf{E}$} & \multicolumn{2}{|c|}{ Tempo de serviço } & \multirow[b]{2}{*}{$x^{2}$} & \multirow[b]{2}{*}{$\mathbf{E}$} & \multicolumn{2}{|c|}{ Utilização } & \multirow{3}{*}{$\begin{array}{c}x^{2} \\
30,624\end{array}$} \\
\hline & & Masculino & Feminino & & & +10 anos & -10 anos & & & Alto & Baixo & \\
\hline Fácil & 84 & 71 & 13 & 0,221 & 84 & 53 & 31 & 4,131 & 84 & 78 & 6 & \\
\hline Difícil & 37 & 30 & 7 & 0,639 & 37 & 16 & 21 & $0,042^{* x}$ & 37 & 18 & 19 & $0,000^{\circ}$ \\
\hline & 121 & 101 & 20 & & 121 & 69 & 52 & & 121 & 96 & 25 & \\
\hline
\end{tabular}

Painel B - Utilidade da TI no trabalho de auditoria fiscal

\begin{tabular}{|c|c|c|c|c|c|c|c|c|c|c|c|c|}
\hline & \multirow[b]{2}{*}{$E$} & \multicolumn{2}{|c|}{ Sexo } & \multirow[b]{2}{*}{$x^{2}$} & \multirow[b]{2}{*}{$\mathbf{E}$} & \multicolumn{2}{|c|}{ Tempo de serviço } & \multirow[b]{2}{*}{$x^{2}$} & \multirow[b]{2}{*}{ E } & \multicolumn{2}{|c|}{ Utilização } & \multirow[b]{2}{*}{$x^{2}$} \\
\hline & & Masculino & Feminino & & & +10 anos & -10 anos & & & Alto & Baixo & \\
\hline Muito útil & 108 & 91 & 17 & $\hat{0,453^{a}}$ & 108 & 64 & 44 & 2,048 & 108 & 91 & 17 & 14,847 \\
\hline Pouco útil & 13 & 10 & 3 & 0,501 & 13 & 5 & 8 & 0,152 & 13 & 5 & 8 & $0,000^{\circ}$ \\
\hline Tota & 121 & 101 & 20 & & 121 & 69 & 52 & & 121 & 96 & 25 & \\
\hline
\end{tabular}

Painel C - Velocidade de realização das tarefas

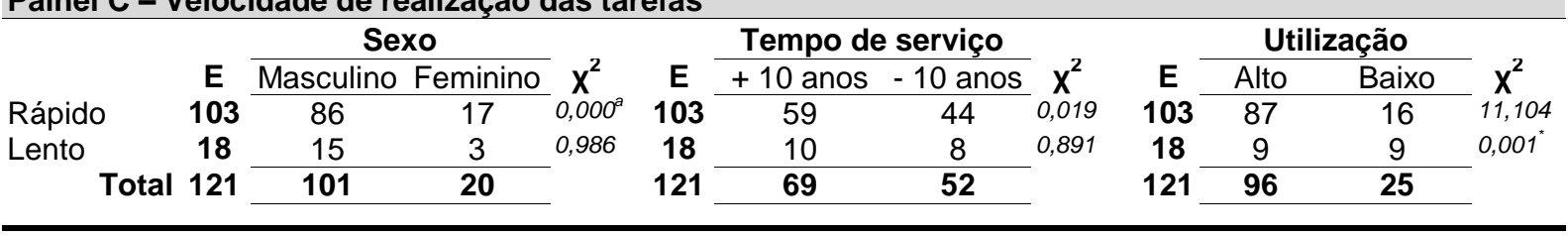

Tabela 1 - Percepção do Auditor Fiscal sobre a execução do trabalho

Notas: (a) aplicada a correção de continuidade de Yates, pois o valor esperado de uma célula foi inferior a cinco. $\quad$ * significante a $1 \%$; ${ }^{\star *}$ significante a $5 \%$; $\mathrm{e}^{\star \star \star}$ significante a $10 \%$.

O painel A da Tabela 1 apresenta as relações existentes entre o nível de dificuldade das ferramentas de TIC e as variáveis sexo, tempo de serviço e nível de utilização dos recursos de TIC. Os resultados indicam que a percepção dos auditores sobre a dificuldade para utilizar as ferramentas de TIC não apresenta diferença de proporção, estatisticamente significante, quando analisado o sexo dos respondentes $\left[\left(\mathbf{x}^{2}(1)=0,221(\mathrm{p}>0,10)\right]\right.$, ou seja, aceita-se a hipótese nula $\mathbf{H}_{\mathrm{ai}} \mathrm{e}$ conclui-se que o nível de dificuldade percebido pelo auditor não está associado ao fato de ser do sexo masculino ou feminino. Por outro lado, ao comparar o nível de dificuldade com o tempo de serviço e o nível de utilização das ferramentas de TIC, identificam-se diferenças significativas entre as frequências observadas e esperadas, i.e., existem evidências estatísticas para rejeitar as hipóteses nulas $\mathbf{H}_{\mathrm{bi}} \mathrm{e}$ $\mathbf{H}_{\mathrm{ci}}$, e concluir que o nível de dificuldade percebida está associado com o tempo de serviço do auditor fiscal $\left[\left(\mathrm{x}^{2}(1)=4,131 \quad(\mathrm{p}<0,5)\right]\right.$ e com o nível de utilização das ferramentas de $\operatorname{TIC}\left[\left(\mathbf{x}^{2}(1)=30,624(\mathrm{p}<0,01)\right]\right.$. O resultado demonstra que os auditores mais antigos têm mais facilidade para o uso das ferramentas de TIC, quando comparado com os novos auditores (77\% contra 59\%, respectivamente); e, ainda, que esta facilidade para o uso das ferramentas de TIC é maior entre aqueles auditores que mais as utilizam ( $81 \%$ contra $24 \%$, que fazem pouco uso delas). Essas constatações podem estar relacionadas à maior experiência e familiaridade de alguns auditores com as ferramentas de TIC utilizadas na realização de suas atividades de auditoria fiscal. 
Revista Tecnologia e Sociedade, Curitiba, v. 11, n. 23, 2015

ISSN (versão online): 1984-3526

ISSN (versão impressa): 1809-0044

O painel B da Tabela 1 apresenta as relações existentes entre a utilidade da TIC no trabalho do auditor e as variáveis sexo, tempo de serviço e nível de utilização. Os resultados indicam que a percepção dos auditores sobre a utilidade da TIC não apresenta diferença de proporção, estatisticamente significante, quando analisado o sexo e o tempo de serviço dos fiscais $\left[\left(\mathbf{x}^{2}(1)=0,453(p>0,10)\right]\right.$ e $\left[\left(\mathbf{x}^{2}(1)\right.\right.$ $=2,048(p>0,10)]$, ou seja, aceitam-se as hipóteses nulas $\mathbf{H}_{\text {aii }}$ e $\mathbf{H}_{\text {bii }}$ e conclui-se que a percepção sobre a utilidade da TIC não está associada ao fato do auditor ser do sexo masculino ou feminino, tampouco com o seu tempo de experiência no trabalho, ou seja, a utilidade da TIC é percebida de forma semelhante entre os respondentes. Por outro lado, ao comparar a utilidade com o nível de utilização dos recursos de TIC, observaram-se diferenças significativas entre as frequências observadas e esperadas, i.e., existe evidência estatística para rejeitar a hipótese nula $\mathbf{H}_{\mathrm{cii}} \mathrm{e}$ concluir que a utilidade percebida está associada ao nível de utilização das ferramentas de $\operatorname{TIC}\left[\left(x^{2}(1)=14,847 \quad(p<0,01)\right]\right.$. O resultado demonstra que, proporcionalmente, as ferramentas de TIC foram consideradas mais úteis por aqueles que mais fazem uso delas.

Por fim, o painel $\mathbf{C}$ da Tabela 1 apresenta as relações existentes entre a velocidade de realização das tarefas e as variáveis sexo, tempo de serviço e nível de utilização dos usuários. Os resultados indicam que a percepção sobre a velocidade de realização das tarefas não apresenta diferença de proporção, estatisticamente significante, quando analisado o sexo e o tempo de serviço dos fiscais $\left[\left(x^{2}(1)=0,000(p>0,10)\right]\right.$ e $\left[\left(x^{2}(1)=0,019(p>0,10)\right]\right.$, ou seja, aceitam-se as hipóteses nulas $\mathbf{H}_{\text {aiii }}$ e $\mathbf{H}_{\text {biii }}$ e conclui-se que a velocidade de realização das tarefas não está associada ao fato do auditor ser do sexo masculino ou feminino, tampouco com o seu tempo de experiência no trabalho. Por outro lado, ao confrontar a velocidade na execução das tarefas com o nível de utilização das ferramentas de TIC, observaram-se diferenças significativas de frequências, o que permite rejeitar a hipótese nula $\mathbf{H}_{\text {ciii }}$ e concluir que a velocidade de realização das tarefas está associada ao nível de utilização das ferramentas de TIC $\left[\left(\mathbf{X}^{2}(1)=11,104(p<0,01)\right]\right.$. O resultado demonstra que a realização das tarefas foi considerada mais rápida por aqueles que mais utilizam as ferramentas de TIC, i.e., a familiaridade com as ferramentas de TIC possibilita a realização de atividades de auditoria fiscal em menor tempo. 
Revista Tecnologia e Sociedade, Curitiba, v. 11, n. 23, 2015

ISSN (versão online): 1984-3526

ISSN (versão impressa): 1809-0044

Em síntese, constatou-se que quanto mais o auditor utiliza as ferramentas de TIC, maior a velocidade dos serviços realizados, maior a utilidade percebida e maior a facilidade para realização das tarefas. Assim, pode-se concluir que a execução dos serviços de auditoria fiscal é impactada pela TIC, já que os usuários frequentes das ferramentas tecnológicas adquirem familiaridade com as mesmas e realizam as atividades de auditoria fiscal em menor tempo.

\section{PERCEPÇÃO SOBRE OS RESULTADOS DO TRABALHO}

A percepção do auditor fiscal sobre os resultados do trabalho de auditoria está representada pela acurácia, pela produtividade do trabalho e pela percepção sobre o nível de redução da sonegação fiscal. São atributos que associados às variáveis sexo, tempo de serviço e nível de utilização, avaliaram a existência de relação estatisticamente significante entre as variáveis, por meio do teste quiquadrado $\left(x^{2}\right)$, conforme Tabela 2.

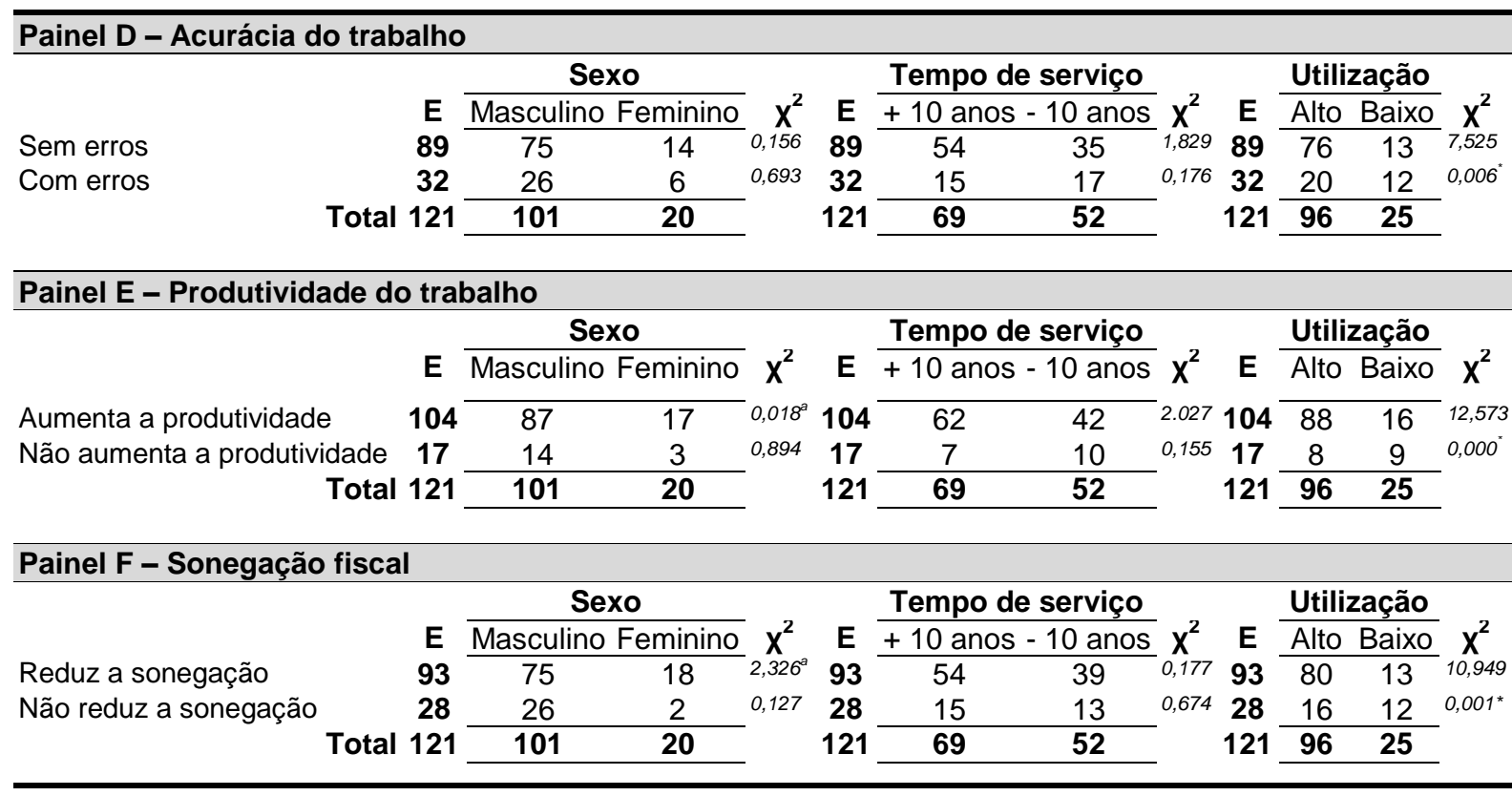

Tabela 2 - Percepção do Auditor Fiscal sobre os resultados do trabalho Notas: (a) aplicada a correção de continuidade de Yates, pois o valor esperado de uma célula foi inferior a cinco; * significante a $1 \% ;{ }^{\star \star}$ significante a $5 \%$; $e^{\star \star \star}$ significante a $10 \%$.

O painel $\mathbf{D}$ da Tabela 2 apresenta as relações existentes entre a acurácia do trabalho realizado e as variáveis sexo, tempo de serviço e nível de utilização dos recursos de TIC. Os resultados indicam que a percepção dos auditores sobre a acurácia do trabalho não apresenta diferença de proporção, estatisticamente significante, quando analisado o sexo e o tempo de serviço dos respondentes $\left[\left(\mathbf{x}^{2}\right.\right.$ 
Revista Tecnologia e Sociedade, Curitiba, v. 11, n. 23, 2015

ISSN (versão online): 1984-3526

ISSN (versão impressa): 1809-0044

(1) $=0,156(p>0,10)]$ e $\left[\left(x^{2}(1)=1,829(p>0,10)\right]\right.$, ou seja, aceitam-se as hipóteses nulas $\mathbf{H}_{\mathrm{di}}$ e $\mathbf{H}_{\mathrm{ei}}$ e conclui-se que o nível acurácia do trabalho não está associado ao fato do auditor ser do sexo masculino ou feminino e, ainda, que a experiência do auditor não é capaz de evitar erros nos resultados do trabalho de auditoria. Por outro lado, ao comparar a acurácia do trabalho com o nível de utilização das ferramentas de TIC, observaram-se diferenças significativas entre as frequências observadas e esperadas, ou seja, existem evidências estatísticas para rejeitar a hipótese nula $\mathbf{H}_{\mathrm{fi}} \mathrm{e}$ concluir que o nível acurácia está associado ao nível de utilização das ferramentas de TIC $\left[\left(X^{2}(1)=7,525(p<0,01)\right]\right.$. O resultado revela que os auditores fiscais, independentemente de sua experiência, quando utilizam com frequência as ferramentas de TIC, erram menos na execução de suas tarefas (20\%, contra $48 \%$ que fazem pouco uso delas).

O painel E da Tabela 2 apresenta as relações existentes entre a produtividade do trabalho realizado e as variáveis sexo, tempo de serviço e nível de utilização dos recursos de TIC. Os resultados indicam que a percepção dos auditores sobre a produtividade do trabalho não apresenta diferença de proporção, estatisticamente significante, quando analisado o sexo e o tempo de serviço dos respondentes $\left[\left(x^{2}(1)=0,018(p>0,10)\right]\right.$ e $\left[\left(x^{2}(1)=2,027(p>0,10)\right]\right.$, ou seja, aceitamse as hipóteses nula $\mathbf{H}_{\mathrm{dii}}$ e $\mathbf{H}_{\mathrm{eii}}$ e conclui-se que a produtividade do trabalho percebida pelo auditor não está associada ao fato de ser do sexo masculino ou feminino, ou com seu tempo de experiência no trabalho, i.e., nem o sexo nem a experiência do auditor são capazes de determinar maior produtividade do trabalho. Por outro lado, ao comparar a produtividade com o nível de utilização das ferramentas de TIC, observou-se diferença significativa entre as frequências observadas e esperadas, havendo evidências estatísticas para rejeitar a hipótese nula $\mathbf{H}_{\mathrm{fii}}$ e concluir que a produtividade do trabalho está associada ao nível de utilização das ferramentas de TIC $\left[\left(x^{2}(1)=12,573(p<0,01)\right]\right.$. Ou seja, entre os auditores que utilizam com frequência as ferramentas de TIC, a maior parte percebe um aumento na produtividade de seu trabalho, quando comparado com os que fazem menor uso delas ( $91 \%$ contra $64 \%$, respectivamente).

Por fim, o painel $\mathbf{F}$ da Tabela 2 apresenta as relações existentes entre o nível de sonegação fiscal e as variáveis sexo, tempo de serviço e nível de utilização dos recursos de TIC. Os resultados indicam que a percepção dos auditores sobre o nível de sonegação fiscal não apresenta diferença de proporção, estatisticamente 
Revista Tecnologia e Sociedade, Curitiba, v. 11, n. 23, 2015

ISSN (versão online): 1984-3526

ISSN (versão impressa): 1809-0044

significante, quando analisado o sexo e o tempo de serviço dos respondentes [ $\left(\mathbf{X}^{2}\right.$ $(1)=2,326(p>0,10)]$ e $\left[\left(x^{2}(1)=0,177(p>0,10)\right]\right.$. Ou seja, aceitam-se as hipóteses nulas $\mathbf{H}_{\text {diii }}$ e $\mathbf{H}_{\text {eiii }}$ e conclui-se que o nível de redução da sonegação fiscal percebido pelo auditor não está associado ao sexo masculino ou feminino do auditor, tampouco com seu tempo de experiência no trabalho. Por outro lado, ao comparar a percepção sobre a sonegação fiscal com o nível de utilização das ferramentas de TIC, observou-se diferença significativa entre as frequências observadas e esperadas, com evidências para rejeitar a hipótese nula $\mathbf{H}_{\text {fiii }}$ e concluir que o nível de sonegação fiscal percebido está associado ao nível de utilização das ferramentas de $\operatorname{TIC}\left[\left(\mathrm{X}^{2}(1)=10,949(\mathrm{p}<0,01)\right]\right.$, i.e., entre os usuários frequentes das ferramentas tecnológicas, uma quantidade significativa percebe que a TIC contribui para a redução da sonegação fiscal, quando comparado com os profissionais que fazem menos uso delas (83\% contra 52\%, respectivamente). Nesse sentido, Soares Júnior (2007) aferiu que, em $90 \%$ dos casos, a utilização de ferramentas de TIC no suporte à auditoria proporciona maior velocidade à recuperação do crédito tributário, enquanto o emprego de dados eletrônicos viabiliza a realização de outros levantamentos, além do planejado.

Em síntese, constatou-se que quanto mais o auditor utiliza as ferramentas de TIC, maior a percepção da acurácia, da produtividade do trabalho e da redução da sonegação fiscal. Diante do exposto, é razoável inferir que os resultados do trabalho de auditoria são impactados pela TIC, na medida em que os usuários frequentes destas ferramentas perceberam resultados mais eficientes, evidências que corroboram com as observações de Soares Júnior (2007).

No que se refere à melhoria do trabalho e das qualificações do auditor, quase todos os respondentes contribuíram apresentando sugestões ou demandas para serem analisadas. Por meio da análise de conteúdo buscou-se interpretar essas mensagens, cujas informações sistemáticas auxiliaram na compreensão dos significados dos textos. As palavras que mais apareceram nas respostas enviadas foram "treinamento" (48 ocorrências), "investimento" em equipamentos ou softwares (26 ocorrências), cursos (24 ocorrências) e "qualificação" (19 ocorrências), i.e., apesar das percepções dos auditores sobre o potencial que a TIC pode trazer para a instituição, ainda persistem problemas relacionados a investimento no capital social que limitam a obtenção de melhores resultados. 
Revista Tecnologia e Sociedade, Curitiba, v. 11, n. 23, 2015

ISSN (versão online): 1984-3526

ISSN (versão impressa): 1809-0044

\section{CONSIDERAÇÕES FINAIS}

Há algum tempo, a TIC deixou de ser suporte para gestão de processos de trabalho e assumiu o protagonismo na administração gerencial das organizações, exigindo profissionais altamente capacitados. A presente pesquisa relata a experiência de uma unidade fazendária que se utiliza destes recursos no exercício da atividade de fiscalização de tributos. O objetivo foi analisar os impactos das novas ferramentas tecnológicas no trabalho de auditoria fiscal e, para tanto, a partir do perfil do auditor, buscou-se identificar sua percepção sobre a influência da TIC na execução de suas atividades, bem como nos resultados de seu trabalho. Adicionalmente, como forma de corrigir fragilidades na formação e capacitação desse pessoal, coletou-se sugestões para melhorar a qualificação do auditor.

Os resultados apontam para a existência de relação estatisticamente significante entre as variáveis investigadas. $\mathrm{Na}$ execução dos serviços, identificouse que os auditores mais antigos têm mais facilidade para o uso das ferramentas de TIC, quando comparado com os novos auditores e, que os usuários frequentes destas ferramentas consideram-nas mais úteis e mais fáceis de serem utilizadas, além de possibilitarem a realização de tarefas em menor tempo. Quanto aos resultados do trabalho, observou-se que os usuários frequentes daquelas ferramentas erram menos na execução de suas tarefas, percebem uma redução da sonegação fiscal e um aumento na produtividade. Em síntese, constatou-se que o uso frequente das ferramentas de TIC reduz os erros e o tempo de execução dos serviços, facilita a realização das tarefas, aumenta a produtividade no trabalho e reduz a sonegação fiscal, ou seja, as ferramentas de TIC conduzem a resultados mais eficientes, evidências que corroboram com as observações de Soares Júnior (2007), sendo possível concluir que a execução dos serviços e os resultados do trabalho de audtoria fiscal são impactados pelas inovações tecnológicas.

Observou-se, ainda, que grande parte dos respondentes possui mais de uma formação e estão compreendidos na faixa etária que abarca adultos de meia idade e idosos o que, segundo Oliveira e Salles (2004), retrata uma mudança no perfil da população que implicará em grande impacto na forma de gerir, capacitar e absorver o capital intelectual das organizações.

Os resultados revelam a importância da TIC no trabalho de auditoria fiscal de uma Secretaria de Fazenda e demonstram que essa atividade é diretamente afetada 
Revista Tecnologia e Sociedade, Curitiba, v. 11, n. 23, 2015

ISSN (versão online): 1984-3526

ISSN (versão impressa): 1809-0044

pelas novas tecnologias disponibilizadas. Espera-se que os achados da pesquisa possam ser vislumbrados pelos órgãos públicos como fomento à utilização de modernas ferramentas de TIC no atingimento de suas metas e finalidades. Ademais, a metodologia adotada no estudo pode servir para pesquisas futuras que se proponham a avaliar o impacto da TIC em outros órgãos públicos ou empresas privadas.

\section{AGRADECIMENTOS}

Os autores agradecem aos ilustres pareceristas da Revista Tecnologia e Sociedade pelas críticas e sugestões feitas à versão original do texto.

\section{REFERÊNCIAS}

BARBOSA. A. M. R. As implicações da tecnologia da informação na profissão contábil. In: Congresso Brasileiro de Contabilidade, XVI., Goiânia, 2000. Anais... Goiânia, 2000. In: CdRoom.

BARROS, M. et al. Nota fiscal eletrônica. Trabalho de Conclusão de Curso. Curso de Graduação em Ciências Contábeis. Centro Universitário Católico Salesiano Auxilium. Lins, 2008.

BEVIR, M.; RHODES, R.; WELLER, P. Traditions of governance: interpreting the changing role of the public sector. Public Administration, v. 81, $\mathrm{n}^{\circ}$ 1, 2003.

BRASIL. Decreto n. 6.022, de 22 de janeiro de 2007. Institui o Sistema Público de Escrituração Digital - SPED. Disponível em: <www.planalto.gov.br/ccivil_03/_Ato20072010/2007/Decreto/D6022.htm>. Acesso em: 3 de novembro de 2010.

BRASIL. RECEITA FEDERAL DO BRASIL. Portal da Nota Fiscal Eletrônica. Disponível em: < http://www.nfe.fazenda.gov.br/portal/justificativa>. Acesso em: 03 de novembro de 2010.

CARDOZO, J. S. Procedimentos de Auditoria. Revista Brasileira de Contabilidade, 91, 1995.

CARRIERI, A. P. Uma opção teórico-metodológica para pesquisas sobre culturas nas organizações. In: CARRIERI, A. P.; CAVEDON, N. R.; SILVA, A. R. L. Cultura nas organizações: uma abordagem contemporânea. Curitiba: Juruá, 2008. p. 19-33.

CHRISPINO, A. Ciência, Tecnologia e Sociedade. Curso de Especialização em Educação Tecnológica. Rio de Janeiro: Centro Federal de Educação Tecnológica Celso Suckow da Fonseca, RJ, 2009, 215p.

CONDÉ, R. A. D. Fraudes Corporativas: um estudo de casos múltiplos à luz da teoria dos escândalos corporativos. 2013. 101 f. Dissertação (Mestrado em Ciências Contábeis), Faculdade de Administração e Finanças da UERJ, Rio de Janeiro. 2013. 
Revista Tecnologia e Sociedade, Curitiba, v. 11, n. 23, 2015

ISSN (versão online): 1984-3526

ISSN (versão impressa): 1809-0044

CORNACHIONE Jr., E. B. Informática aplicada às áreas de contabilidade, administração e economia. 3. ed. São Paulo: Atlas, 2001.

CRUZ, N.V.S. et al. O Impacto da Tecnologia da Informação no Profissional Contábil. VIII Congresso Internacional de Custos. Anais... Punta del Leste: Uruguai. 2003.

EVANGELISTA, K. Z. dos S. Transformações societárias, envelhecimento e novas tecnologias: os impactos da informática na vida dos idosos. 2010. 95f. Monografia (Graduação em Serviço Social). Universidade Federal de Santa Catarina, Florianópolis, 2010.

FAVERO, C. G. Avaliação de Programas Públicos. Sistema de Avaliação do Programa Nacional de Gestão Pública e Desburocratização aplicado à Marinha do Brasil: O Caso do Programa Netuno. 2010. Dissertação (Mestrado em Administração). Fundação Getúlio Vargas, Rio de Janeiro, RJ, 2010.

FRANCISCO, S.; RONCHI, S. H.; MECHELN, P. J. V. Os Impactos da Implantação do Sistema Público de Escrituração Digital (SPED) na Gestão das Micro e Pequenas Empresas. 2008. In: $2^{\circ}$ Congresso UFSC de Controladoria e Finanças. Anais... Disponível em: <http://dvl.ccn.ufsc.br/congresso/anais/2CCF/index.htm>. Acesso em: 03 de novembro de 2012.

GIL, A. C. Métodos e técnicas de pesquisa social. São Paulo: Atlas, 2009.

HENDRIKSEN, E. S.; BREDA, M. F. V. Teoria da Contabilidade. São Paulo: Atlas, 1999.

MARKUS, L. M.; ROBEY, D. Information Technology and Organizational Change: Causal Structure in Theory and Research. Management Science, Vol.34, n. 5, May 1988, p.583598.

MERCHANT, K. A. Modern management control systems: text \& cases. Upper Saddle River: Prentice-Hall, 1998.

MEYERSON, D.; MARTIN, J. Cultural change: an integration of three different views. Journal of Management Studies, v. 24, n. 4, p. 623-647, 1987. Disponível em: http://dx.doi.org/10.1111/j.1467-6486.1987.tb00466.x Acesso em: 10 de dezembro de 2014.

MOMM, L. C. Projeto Educação Continuada: Nota Fiscal Eletrônica, Escrituração Fiscal Digital e as últimas alterações na Legislação. Florianópolis, 2008.

MORAES, R. Análise de conteúdo. Educação, Porto Alegre, v.22, n.37, p.7-32, 1999.

MOURA, I, J. L.; SILVA, M, V, P.; DIAS, G, M, A. Perspectivas da Profissão Contábil no Brasil. Portal Classe Contábil, 2004.2 Disponível em:<http://www.portaladm.adm.br/Cl/Cl20.pdf>. Acesso em: 04 de maio de 2015.

MOTTA, P. R. Transformação organizacional: a teoria e a prática de inovar. Rio de Janeiro: Qualitymark, 1998.

NASI, A. C. A Auditoria Integral como instrumento de uma gestão eficaz e voltada para novas exigências dos usuários: um desafio definitivo para o auditor independente como agente do desenvolvimento empresarial. In: XXII Conferência Interamericana de Contabilidade. Anais... Lima, Peru. 1997.

NASRI, F. O envelhecimento populacional no Brasil. Einstein, 6 (Supl 1), S4-S6, 2008. 
Revista Tecnologia e Sociedade, Curitiba, v. 11, n. 23, 2015

ISSN (versão online): 1984-3526

ISSN (versão impressa): 1809-0044

OLIVEIRA, C. H. V. R.; SALLES, M. T. O envelhecimento da população e as implicações no capital intelectual das empresas. Simpósio de Excelência em Gestão e Tecnologia, Anais... Resende, 2004.

PADOVEZZE, C. L. Sistemas de Informações Contábeis. 2. ed. São Paulo: Atlas, 2000.

PEREIRA, M T F; BECKER, J L. Impacto da Tecnologia da Informação sobre o Processo de Trabalho Individual: estudo em um grande banco brasileiro. Atibaia, XXVII ENANPAD, Anais.. 2003. 14f.

POLLIT, C.; BOUCKAERT, G.: Public Management Reform: A Comparative Analysis. Oxford University Press. Dezembro, 1999.

PORTAL TRIBUTÁRIO. Sistema Público de Escrituração Digital - SPED. Disponível em $<$ www.portaltributario.com.br>. Acesso em 03 de novembro de 2010.

ROLT, A. P. A Utilização de Ferramentas de Gov-e: um estudo de caso na Secretaria de Estado da Fazenda de Santa Catarina. Trabalho de Conclusão de Curso. Curso de Graduação em Administração Pública. Universidade do Estado de Santa Catarina. Florianópolis, 2012.

SANTOS, B. L.; PEFFERS, K. "The Effects of Early Adoption of Information Technology: Empirical Study." Proceedings of the Twelfth International Conference on Information Systems. Proceedings... New York, December, 1991, p.16-18.

SILVA, M. S. As repercussões do Sistema Público de Escrituração Digital - SPED: uma análise da percepção de empresas, contadores e órgãos fiscalizadores na região metropolitana de Belo Horizonte/MG. Dissertação. Mestrado em Administração. Fundação Pedro Leopoldo. Pedro Leopoldo, 2012

SOARES JÚNIOR, J. B. Utilização da tecnologia da informação pelo Fisco estadual cearense: o entrelaçamento de bases de dados de contribuintes do ICMS como ferramenta de auditoria fiscal. Dissertação. Universidade Federal do Ceará. Mestrado Profissional em Controladoria. Fortaleza, 2007.

STREINER, D. L. Being inconsistent about consistency: when coefficient alpha does and doesn't matter. Journal of Personality Assessment. v. 80, p. 217-222. 2003.

TORKZADEH, G. e DOLL, W. The Development of a Tool for Measuring the Perceived Impact of Information Technology on Work. The International Journal of Management Science, Volume 27, Junho, 1999, pp. 327-339.

VERGARA, S C. Métodos de Pesquisa em Administração. São Paulo, 2010.

VIANA, M. A. Comprometimento organizacional: estudo comparativo dos grupos geracionais em uma Universidade Federal. Dissertação. Mestrado em Administração. Fundação Pedro Leopoldo. Pedro Leopoldo, 2012. 
Revista Tecnologia e Sociedade, Curitiba, v. 11, n. 23, 2015

ISSN (versão online): 1984-3526

ISSN (versão impressa): 1809-0044 